\title{
GROWTH RATE OF CRYSTALS WITHIN THE SURFACE-SNOW/FIRN LAYER IN WILKES LAND, EAST ANTARCTICA
}

\author{
by
}

\author{
Qin Dahe
}

(Lanzhou Institute of Glaciology and Geocryology, Academia Sinica, Lanzhou, Gansu, People's Republic of China)

and

Neal W. Young and Richard J. Thwaites

(Australian Antarctic Division, Channel Highway, Kingston, Tasmania 7050, Australia)

\section{ABSTRACT}

Measurements of crystal size have been made on seven firn cores drilled at sites covering a range of mean annual temperature from $-12.6^{\circ}$ to $-52.5^{\circ} \mathrm{C}$ and a range of accumulation rate from 52 to $315 \mathrm{~kg} \mathrm{~m}^{-2} \mathrm{a}^{-1}$. The sorting coefficient, which gives a measure of the dispersion of crystal sizes within a sample, shows an overall pattern when data from all cores are grouped together as a function of depth. The values are generally small near the surface, increasing to a maximum around $8 \mathrm{~m}$ depth, then decreasing but becoming more diffuse at greater depths. Below about $5 \mathrm{~m}$ depth, the crystal size increases at an essentially constant rate, which depends on temperature, but in the upper 5 or $7 \mathrm{~m}$ the size increases at 1.5 to 2 times this rate. The seasonal variation in temperature enhances the effective mean growth rate of crystals in the near-surface layers compared to conditions with a constant mean temperature and accounts for a part of that increase. But it is likely that vapour diffusion along strong vertical temperature gradients causes the greater part of the observed increase in growth rate. The dependence of crystal-growth rate on temperature is consistent with the Arrhenius-type relation found by other studies.

\section{INTRODUCTION}

An overall aim of this work is to determine the distribution of crystal size in the upper $20 \mathrm{~m}$ of the Antarctic snow cover and to obtain estimates of the crystal-growth rate at sites for a range of values of mean annual temperature and snow-accumulation rate, as part of a larger investigation of the characteristics of the snow cover.

The methodology of crystal-size measurement by cross-section area, employed by Gow $(1969,1975)$, is followed with only some modification to allow comparison with his work and that of Alley and others (1982). Samples were cut at regular intervals along the core and crystal sizes were measured on scaled photomicrographs. The ages of the samples are calculated, using measured density-depth profiles and accumulation rates derived from stake measurements. Change in the form of the crystal-size distributions with depth is discussed, using the sorting coefficient as a measure of the dispersion of sizes within a sample. Taking mean values from each sample, crystal size is found to increase approximately linearly with depth over the length of the core. In the lower part of each core, below about $5 \mathrm{~m}$ depth, the crystal size increases essentially linearly with time. But in the upper few metres of the snow cover the crystal-growth rate is greater than that below $5 \mathrm{~m}$ by a factor of 1.5 to 2 . The effect of the seasonally varying temperature regime in the upper layers on the growth rate there is investigated by comparing the mean growth rate calculated for a time-varying temperature regime with that for a constant temperature. The measured crystal-growth rates are compared with measurements obtained by other workers, and differences are discussed in terms of the measurement technique used and the dependence of growth rate on temperature.

\section{SAMPLE PREPARATION AND CRYSTAL-SIZE MEASUREMENT}

Cores were collected from seven sites in Wilkes Land, with a range in accumulation rate from 52 to $315 \mathrm{~kg} \mathrm{~m}^{-2}$ $\mathrm{a}^{-1}$ and in temperature from $-12.6^{\circ}$ to $-52.5^{\circ} \mathrm{C}$. Three of these sites are on Law Dome, and the remaining four are located along an oversnow traverse route from Casey Station, south to about lat. $74.2^{\circ} \mathrm{S}$ between long. $110^{\circ}$ and $112^{\circ} \mathrm{E}$ (Fig. 1). The cores were drilled with a PICO light-weight hand-coring auger system which achieved 95-99\% core recovery. All cores were returned to Casey Station, where they were stored at a temperature of from $-18^{\circ}$ to $-14^{\circ} \mathrm{C}$. The main characteristics of the sites and cores are summarized in Table I.

Wherever possible, samples were cut at regular intervals down each core: horizontal sections at about $1 \mathrm{~m}$ intervals, and vertical sections at $5 \mathrm{~m}$ intervals, plus a few additional vertical sections at intervening depths. The best coverage was attained on the cores from the Law Dome sites. Cutting and thin-section preparation occurred from 1 to 4 months after drilling. First, aniline and, later, dodecane were used as fillers to impregnate the porous firn and support the crystalline structure during slicing, similar to the methods described by Gow (1969) and Alley (1980).

Scaled photomicrographs of the thin sections were taken in polarized light, in order to distinguish the individual crystals. A rectangular area was marked on each photograph and divided into sub-rectangles that contained about 20-40 crystals each. All crystals in a sub-rectangle were measured, as were those in additional sub-rectangles until a total of 100-120 crystals was reached. Crystal length and width are defined as the diameter of the smallest circumscribed circle and the diameter of the largest inscribed circle respectively. The area of each crystal is then calculated, assuming it has an elliptical shape with major and minor axes determined by this length and width. The individual crystal sizes in a section were then ranked and the mean was calculated for the 50 largest crystals in the sample. Selection of the sample area is arbitrary but the rest of the technique should avoid subjectivity to a great extent. This technique differs from that of Gow (1969) and Alley (1980) in that they selected their crystals from sample 


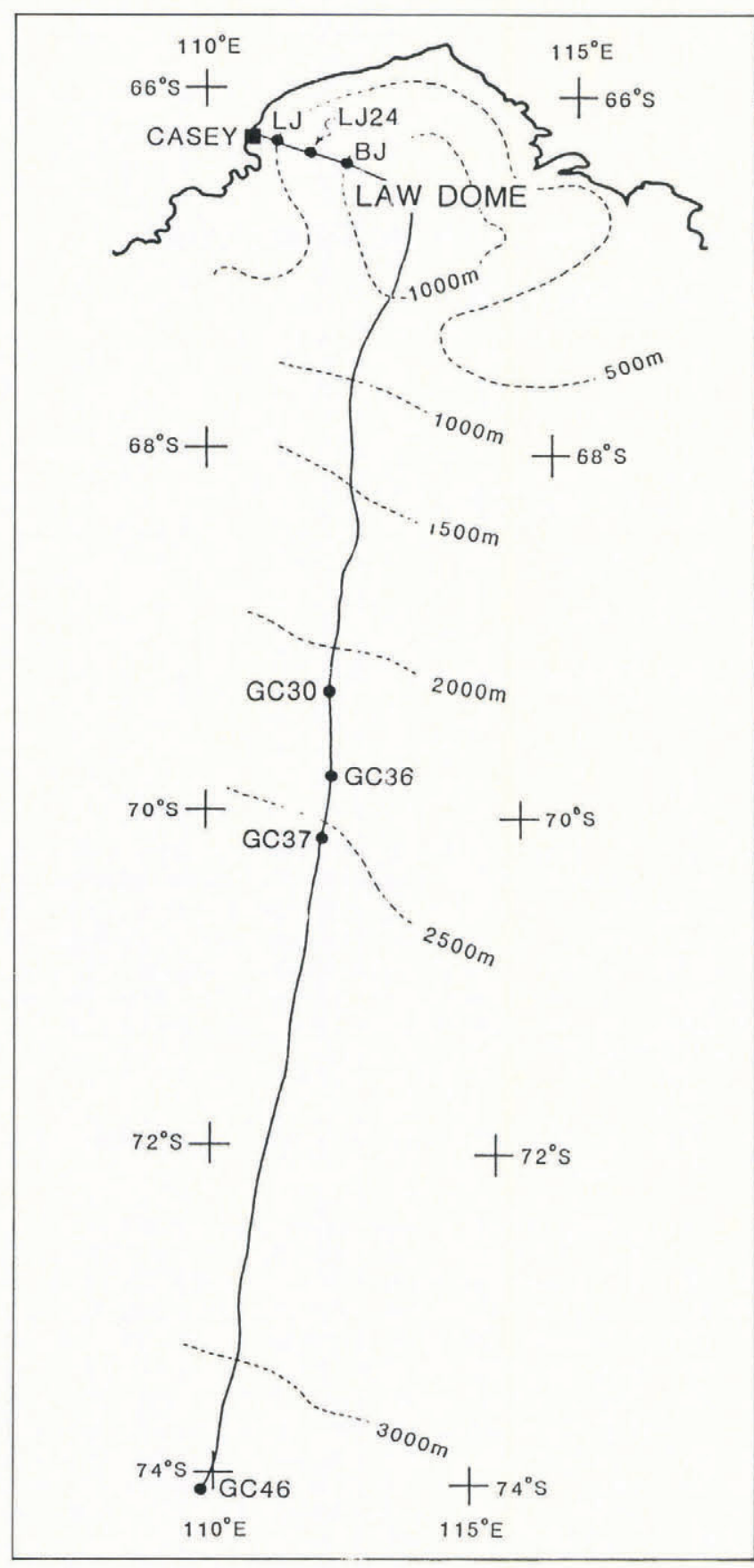

Fig. 1. Map showing the locations of the sampling sites in Wilkes Land, Antarctica. areas of a constant size on the thin sections of $17.5 \mathrm{~mm} \times 12.5 \mathrm{~mm}$ and $30 \mathrm{~mm} \times 17.5 \mathrm{~mm}$ respectively. Gow $(1969,1975)$ chose the 50 largest crystals within the sample area, whereas Alley (1980) rejected the five largest before calculating the mean area of the next largest 50 . Crystal sizes are generally in the range $0.1-0.2 \mathrm{~mm}^{2}$ close to the surface and vary between 0.2 and $3 \mathrm{~mm}^{2}$ at $10 \mathrm{~m}$ depth. In some cores, measurements from the vertical sections differed noticeably from the results from the horizontal sections. So the analysis for growth rates is restricted to the horizontal sections for consistency and because they are more numerous.

\section{AGE CALCULATION}

Age-depth profiles are calculated for each site, using the measured snow-accumulation rate and density-depth profile (Qin and Young 1988, this volume). For the four southern sites, the accumulation rate was measured on stakes over a 6 year interval. On Law Dome the stake measurements were made over various intervals up to 20 years. For the calculation, the accumulation rate is assumed to be constant over the time interval represented by the core, and equal to the measured accumulation rate. At two sites there is considerable horizontal movement of the surface along a lateral accumulation gradient during the time interval represented by the firn core, which must be allowed for in the age calculations. At GC36, the displacement is about $3.2 \mathrm{~km}$ over 81 years, and the accumulation rate reduces from 220 to $42 \mathrm{~kg} \mathrm{~m}^{-2} \mathrm{a}^{-1}$ over that distance. At GC37 the accumulation rate reduces from 150 to $105 \mathrm{~kg} \mathrm{~m}^{-2} \mathrm{a}^{-1}$ over the $2.4 \mathrm{~km}$ moved in 77 years. The accumulation measurements were made on stakes spaced at $2 \mathrm{~km}$ intervals, and indicated a decrease at the stakes that is linear with distance. The gradient is assumed to be linear over the interval between the stakes.

In addition, the accumulation rate (averaged over intervals of a decade or more) can vary by $20-30 \%$ around the long-term average (Young and others 1982). Thus, using an accumulation rate which has been measured over a short time interval as an estimate of the long-term average can potentially introduce a bias of $20-30 \%$ in the overall time-scale for each site.

\section{DISTRIBUTION OF CRYSTAL SIZES IN A THIN SECTION}

Measurements were made of all crystals within a sample area, in an attempt to obtain an unbiased estimate of the distribution of crystal sizes in a cross-section. Stephenson (1967) and Gow (1969) discussed briefly the two factors which influence the measured distribution in a thin section: the random intersection of the thin section with a crystal, so that maximum dimensions are generally not represented, and the spatial distribution of sizes of

TABLE I. CHARACTERISTICS OF THE SAMPLE SITES AND CORES

$\begin{array}{lcccccccc}\text { Site } & \text { Latitude } & \text { Longitude } & \begin{array}{c}\text { Elevation } \\ (\mathrm{m})\end{array} & \begin{array}{c}\text { Distance } \\ \text { from coast } \\ (\mathrm{km})\end{array} & \begin{array}{c}\text { Core } \\ \text { length } \\ (\mathrm{m})\end{array} & \begin{array}{c}\text { Age } \\ \text { span } \\ (\mathrm{a})\end{array} & \begin{array}{c}\text { Mean annual } \\ \text { temperature } \\ \left({ }^{\circ} \mathrm{C}\right)\end{array} & \begin{array}{c}\text { Mean annual } \\ \text { accumulation rate } \\ \left(\mathrm{kg} \mathrm{m}^{-2} \mathrm{a}^{-1}\right)\end{array} \\ \mathrm{LJ} & 66^{\circ} 19^{\prime} \mathrm{S} & 110^{\circ} 52^{\prime} \mathrm{E} & 473 & 15 & 20 & 133 & -12.6 & 100 \\ \mathrm{LJ} 24 & 66^{\circ} 23^{\prime} \mathrm{S} & 111^{\circ} 22^{\prime} \mathrm{E} & 765 & 40 & 30 & 125 & -15.5 & 150 \\ \mathrm{BJ} & 66^{\circ} 28^{\prime} \mathrm{S} & 111^{\circ} 58^{\prime} \mathrm{E} & 1043 & 60 & 21 & 159 & -17.7 & 77 \\ \mathrm{GC} 30 & 69^{\circ} 21^{\prime} \mathrm{S} & 111^{\circ} 51^{\prime} \mathrm{E} & 2117 & 360 & 20 & 34 & -33.6 & 315 \\ \mathrm{GC} 36 & 69^{\circ} 48^{\prime} \mathrm{S} & 112^{\circ} 01^{\prime} \mathrm{E} & 2307 & 410 & 20 & 81 & -36.3 & 42-220^{*} \\ \mathrm{GC} 37 & 70^{\circ} 09^{\prime} \mathrm{S} & 111^{\circ} 50^{\prime} \mathrm{E} & 2430 & 450 & 19 & 77 & -38.0 & 105-150^{*} \\ \mathrm{GC} 46 & 74^{\circ} 08^{\prime} \mathrm{S} & 109^{\circ} 50^{\prime} \mathrm{E} & 3090 & 900 & 17 & 154 & -52.5 & 52\end{array}$

${ }^{*}$ GC36 and GC37 are located in areas where there is significant movement of the ice sheet along strong horizontal accumulation gradients. See text. 
individual crystals. Stephenson (1967) noted that "while it is possible to estimate spatial size distribution, it has been shown that the planar crystal size distribution" (from random cross-sections) "is representative of spatial size distribution", and hence it has generally been used without modification.

For a selection of thin sections, Schytt (1958), Stephenson (1967) and Gow (1971) presented distributions of crystal size which exhibited similar character, even though the method of selection of the measured crystals differed. Stephenson (1967) reported an approximately log-normal distribution of crystal sizes in a thin section, where the frequencies had been weighted by crystal size. In this work the unweighted distributions are found to be approximately truncated log-normal for the 50 largest crystals in a section and over a wide range of values of temperature, accumulation rate and sample depth.

The sorting coefficient

$$
C_{\mathrm{S}}=\left(Q_{3} / Q_{1}\right)^{\frac{1}{2}}
$$

where $Q_{1}$ and $Q_{3}$ are the first $(25 \%)$ and third $(75 \%)$ quartile values respectively, is calculated from the ranked data. The values vary mostly between 1.2 and 1.8 and show a varying trend with depth at the different sites. When all data are grouped together as a function of depth, the near-surface $(0-2 \mathrm{~m})$ values are mostly between 1.2 and 1.4 . There is a general increase to a maximum of about 1.5 at around $8 \mathrm{~m}$ depth, then at greater depths the values mainly decrease but become more diverse, mostly in the range 1.2-1.6.

Gow (1969) introduced the method of measuring the 50 largest crystals in a section in order to overcome the underestimation of their true spatial size which was caused by the random intersection of a thin section with a crystal. For material composed of uniformly sized spherical grains, Krumbein's (1935) work indicated that the true diameter will be underestimated by a factor of 1.25 and thus the area will be underestimated by a factor of 1.56. Calculated over all sections studied in this work, the average of the ratio of the mean size for the 50 largest crystals to the mean size for all crystals in a sample area (approximately 100-120 crystals) was 1.65 . The difference between the two numbers is indicative of the range of crystal sizes within a volume of snow/firn; i.e. the spatial distribution is non-uniform.

\section{CRYSTAL-GROWTH RATES}

The crystal size is found to increase essentially linearly with age below about $5 \mathrm{~m}$ depth. As an example, the results from BJ are shown in Figure 2. The crystal growth at each site is calculated from the linear regression of the mean crystal cross-section area against the age of the sample. The values are given in Table II, using data from between $5 \mathrm{~m}$ depth and the bottom of the core, together with values for the intervals $0-7 \mathrm{~m}$ and for the top to bottom of the core. With the data available, no significant difference in calculated growth rates could be observed by using data for depths below $10 \mathrm{~m}$ compared to that for depths below $5 \mathrm{~m}$.

From an inspection of the profiles of crystal size versus age, it is apparent that the growth rate in the upper 5 or $7 \mathrm{~m}$ of the snow cover is generally greater than that calculated for depths below $5 \mathrm{~m}$, except for the profile from LJ (which is the warmest site) and for GC37. At sites GC36 and GC46 there is insufficient data to calculate a growth rate for the upper layer. But, if an initial size in the range $0.1-0.2 \mathrm{~mm}^{2}$ is assumed for the near-surface layers, an estimated value can be obtained. The calculated and estimated values are included in Table II. The data from the upper $7 \mathrm{~m}$ are used for the calculation because there is no sharp change in growth rate with depth and there are typically only a few data points in the top $5 \mathrm{~m}$. At $\mathrm{LJ}$, the growth rate in the upper 5 or $7 \mathrm{~m}$ is not greater than that below $5 \mathrm{~m}$, and at GC37 a similar condition appears to apply.

An explanation for the change in growth rate with depth can be sought in the effect on crystal growth of the temperature regime in the upper layers, caused by the

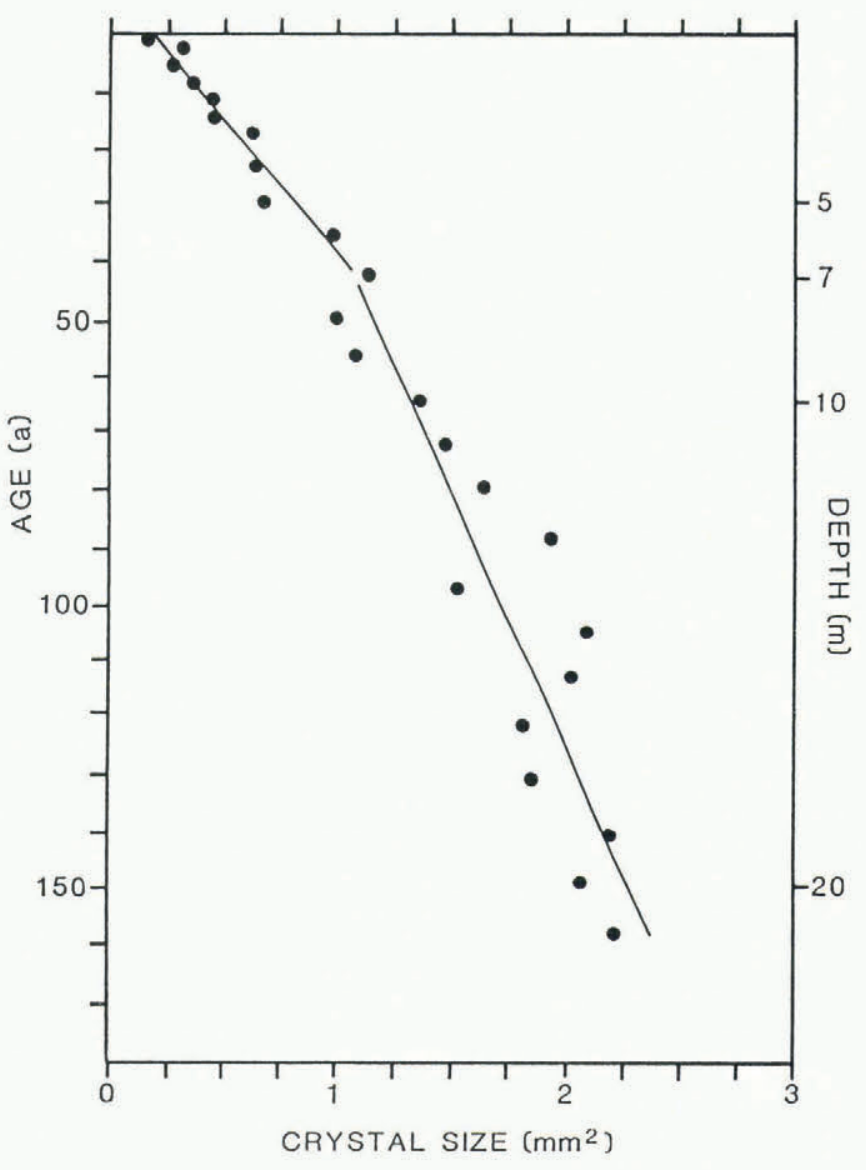

Fig. 2. Mean crystal size plotted as a function of age for BJ. The straight lines are fitted to the data by linear regression, using only the points between the surface and $7 \mathrm{~m}$ depth for the upper line and between $5 \mathrm{~m}$ and the bottom for the lower line, to show the difference in growth rates in the upper layer compared with that in the deeper firn.

TABLE II. CRYSTAL-GROWTH RATES OVER VARIOUS DEPTH INTERVALS

\begin{tabular}{|c|c|c|c|c|}
\hline \multirow[b]{2}{*}{ Site } & \multirow[b]{2}{*}{ Interval: } & \multicolumn{3}{|c|}{ Crystal-growth rate $\left(\mathrm{mm}^{2} \mathrm{a}^{-1} \times 10^{3}\right)$} \\
\hline & & $0-7 \mathrm{~m}$ & $5 \mathrm{~m}-$ bottom & $0 \mathrm{~m}-$ bottom \\
\hline LJ & & $(31.6)$ & 40.1 & 44.5 \\
\hline LJ24 & & 31.3 & 20.8 & 21.0 \\
\hline BJ & & 21.2 & 10.2 & 13.1 \\
\hline GC30 & & 9.9 & 5.1 & 5.6 \\
\hline GC36 & & $3.8^{*}$ & 2.3 & - \\
\hline GC37 & & $(\sim 2.7)$ & 3.0 & $\sim 3.0$ \\
\hline GC46 & & $2.8^{*}$ & 1.2 & - \\
\hline
\end{tabular}

*Values of the crystal-growth rate for $0-7 \mathrm{~m}$ depth at GC36 and GC46 are derived by using an estimated surface-crystal size. See text.

() Values in parentheses, at LJ and GC37, are exceptions to the relation between shallow and deeper growth rates found at other sites. See text.

seasonal variation in temperature, and the development and dissipation throughout the year of strong vertical temperature gradients. Gow (1975) found an Arrhenius-type relation between crystal-growth rate and temperature:

$$
K=K_{0} \exp (-E / R T)
$$


where $K\left(\mathrm{~mm}^{2} \mathrm{a}^{-1}\right)$ is the growth rate of the crystal area, $E=44.5 \times 10^{3} \mathrm{~J} \mathrm{~mol}^{-1}$ is the activation energy, $R$ is the gas constant, and $T$ is the absolute temperature. Equation (2) can be used to calculate the variation in the growth rate over a year, which results from the variation in temperature over a seasonal cycle. Integration of the growth rate over the year then gives a mean value which is found to be greater than the value which would result had the temperature remained constant at a value equal to the mean temperature over a year. Using data from South Pole (Dalrymple and others 1966) as a guide to the expected amplitude of the seasonal temperature variation at a number of depths, the mean annual effective growth rate at each depth can be calculated by using a sinusoidal approximation of the temperature variation in Equation (2). The amplitude of the seasonal temperature variation reduces with depth and the magnitude of the net increase in mean growth rate caused by this variation in temperature reduces even more rapidly with depth. For a site with mean annual temperature of about $-50^{\circ} \mathrm{C}$ and seasonal variation of $\pm 15-20^{\circ} \mathrm{C}$ at the snow surface, the temperature variation at $1.5 \mathrm{~m}$ depth is only $\pm 10^{\circ} \mathrm{C}$, with a net resultant increase in growth rate of $30 \%$ over that for a constant temperature of $-50^{\circ} \mathrm{C}$. By $3 \mathrm{~m}$ depth the variation is only $\pm 3-4^{\circ} \mathrm{C}$ and the net increase in growth rate is less than $5 \%$ and rapidly becomes negligible at greater depths. The actual increase will be a little less than these figures indicate because the assumption of a sinusoidal variation overestimates the duration of warmer temperatures.

The size of the increase in growth rate caused by the seasonal variation reduces with higher mean temperatures; at $-30^{\circ} \mathrm{C}$, a variation of $\pm 10^{\circ} \mathrm{C}$ gives a net increase of only $20 \%$. Data from automatic weather stations located along the traverse route (personal communication from I. Allison) show that the amplitude of the seasonal temperature wave decreases the farther north the site is and the closer it is to the coast. The magnitude of the swing between the mean summer (December, January, February) temperature and the mean winter (June, July, August) temperature at GC46 is $29.1^{\circ} \mathrm{C}$, at GC41 $\left(71^{\circ} 36^{\prime} \mathrm{S}, 111^{\circ} 15^{\prime} \mathrm{E}\right.$; $2759 \mathrm{~m}$ a.s.1.) $23.1^{\circ} \mathrm{C}$, at $\mathrm{AO} 28\left(68^{\circ} 24^{\prime} \mathrm{S}, 112^{\circ} 12^{\prime} \mathrm{E}\right.$; $1630 \mathrm{~m}$ a.s.1.) $17.3^{\circ} \mathrm{C}$, and at Casey Station $\left(66^{\circ} 17^{\prime} \mathrm{S}, 110^{\circ} 33^{\prime} \mathrm{E}\right) 13.8^{\circ} \mathrm{C}$. Thus the effect is greatest for the cold inland sites and can at best explain only a proportion of the increase in growth rate in the top 5 or $7 \mathrm{~m}$ of the snow cover. Gow (1969) suggested that "the much greater rates of growth of grains and crystals in the top $4 \mathrm{~m}$ at the South Pole can probably be attributed to the effects of sustained temperature gradients in a snowpack that is accumulating very slowly". These conditions exist at the inland sites, particularly GC46. In pits and shallow cores, large proportions of the upper few metres were observed to consist of depth-hoar crystals, indicating that there is strong vapour diffusion along the large vertical temperature gradients that occur there. Because of the low accumulation rate, the firn remains under the influence of these near-surface conditions for a long period.

In Figure 3, the crystal-growth rate is plotted against temperature, together with the data of Schytt (1958), Stephenson (1967), Gow $(1969,1975)$ and Alley and others (1982). The solid line is that of Gow (1975). An adjustment is introduced to allow for the difference between Gow's (1969) technique of crystal selection and measurement and this work. Gow $(1969,1975)$ notes that his 50 largest crystals in many sections represent at least $25 \%$ of the total in the sample. The ratio of the mean of the largest 25 in 100 crystals to the largest 50 in 100 crystals averaged over all sections in this work is 1.41. Growth rates obtained from this work, increased by the factor of 1.41, are also plotted in Figure 3. But the number of crystals in Gow's sample area depends on mean crystal size, hence this adjustment is only approximate.

The values from four sites (LJ24, GC30, GC36 and GC37) fall close to the line given by Gow (1975). At GC46, the growth rate appears to be overestimated by a factor of almost 2. This point is based on only nine sets of crystal measurements and on an accumulation rate derived from only a 6 year data interval extrapolated over an estimated 155 years spanned by the core, and hence may be in error by some factor. Site LJ is located in an area that has been disturbed by field activities and so may have an overestimated accumulation rate. In addition, the growth
TEMPERATURE $\left({ }^{\circ} \mathrm{C}\right)$

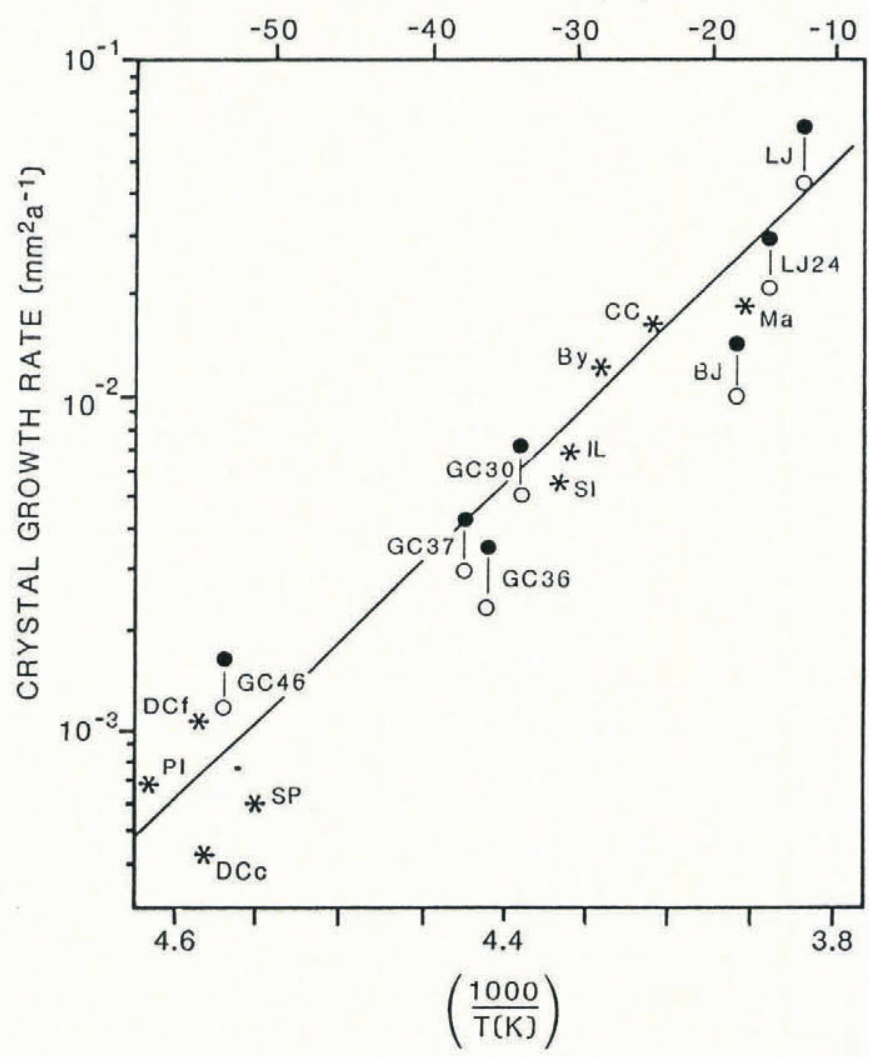

Fig. 3. Temperature dependence of the crystal-growth rate in firn. The logarithm of the growth rate is plotted against the reciprocal of the absolute temperature, $T(K)$. The data from Camp Century (CC), Byrd (By), Inge Lehmann (IL) and Plateau (Pl) are taken from Gow (1975); South Pole (SP) from Gow (1969); Dome C (DCc and DCf) from Alley and others (1982); South Ice (SI) from Stephenson (1967); and Maudheim (Ma) from Schytt (1958). The original measured values obtained from this work are plotted as open circles, and the values adjusted to account for the difference in measurement techniques are represented by solid circles.

process may differ from that at the other sites, since $\mathrm{LJ}$ is not in the dry-snow zone, and surface melting occurs from time to time in the summer months. The result from BJ appears to be anomalous, but it is possible that there is a significant variation in the accumulation rate over a small but pronounced surface topographic feature on which it is located and where the accumulation markers are not sufficiently close to resolve this effect.

\section{CONCLUSIONS}

The following observations and conclusions are made on the basis of this work:

1. For all stations and depths the sorting coefficients of the crystal-size distribution for the 50 largest crystals in each sample are between 1.2 and 1.8. There is some tendency for small values near the surface to increase to a maximum around $8 \mathrm{~m}$ depth and then decrease and become more diverse at greater depths.

2 . The mean crystal size increases approximately linearly with depth, over the length of the core, and essentially linearly with age below about $5 \mathrm{~m}$ depth.

3. Growth rates in the upper 5 or $7 \mathrm{~m}$ are observed to be about 1.5 to 2 times those below $5 \mathrm{~m}$. This difference can be explained by the different temperature regimes. Seasonal temperature variations enhance the growth rate above that expected in isothermal conditions, but this is significant only in the upper 2 or $3 \mathrm{~m}$. The larger part of the increase is probably due to enhanced crystal growth by vapour diffusion along the large temperature gradients that occur in 
the upper layers. The magnitude of the surface seasonal temperature variation and the levels of enhancement of crystal-growth rate described above decrease from the interior towards the coast.

4. When account is taken of the differences in techniques for selecting and measuring crystals, the growth rates derived from this work are close to the Arrhenius-type relationship between crystal-growth rate and temperature found by Gow (1975). Departures from this relation can probably be explained by conditions which are localized to a few of the sites.

\section{ACKNOWLEDGEMENTS}

We thank Dr Ian Allison, Professor Huang Maohuan and $\mathrm{Mr}$ Wang Wenti for their helpful discussions and comments, the reviewers for their suggestions, and the 1984 ANARE glaciology traverse teams for their assistance in obtaining the firn cores.

\section{REFERENCES}

Alley, R.B. 1980. Densification and recrystallization of firn at Dome C, East Antarctica. Ohio State Univ. Inst. Polar Stud. Rep., 77.

Alley, R.B., J.F. Bolzan, and I.M. Whillans. 1982. Polar firn densification and grain growth. Ann. Glaciol., 3, 7-11.

Dalrymple, P.C., H.H. Lettau, and S.H. Wollaston. 1966. South Pole micrometeorology program: data analysis. In Rubin, M.J., ed. Studies in Antarctic meteorology.
Washington, DC, American Geophysical Union, 13-57. (Antarct. Res. Ser., 9.)

Gow, A.J. 1969. On the rate of growth of grains and crystals in south polar firn. J. Glaciol., 8(53), 241-252.

Gow, A.J. 1971. Depth-time-temperature relationships of ice crystal growth in polar glaciers. CRREL Res. Rep., 300.

Gow, A.J. 1975. Time-temperature dependence of sintering in perennial isothermal snowpacks. IAHS Publ. 114 (Symposium of Grindelwald 1974 - Snow Mechanics), $25-41$.

Krumbein, W.C. 1935. Thin section mechanical analysis of indurated sediments. J. Geol., 43(5), 482-496.

Qin Dahe, and N.W. Young. 1988. Characteristics of the initial densification of snow/firn in Wilkes Land, East Antarctica. Ann. Glaciol., 11, 209.

Schytt, V. 1958. Glaciology II. A. Snow studies at Maudheim; B. Snow studies inland; C. The inner structure of the ice shelf at Maudheim as shown by core drilling. Norwegian-British-Swedish Antarctic Expedition, 19491952. Scientific Results, 4.

Stephenson, P.J. 1967. Some considerations of the snow metamorphism in the Antarctic ice sheet in the light of ice crystal studies. In Oura, H., ed. Physics of Snow and Ice. International Conference on Low Temperature Science

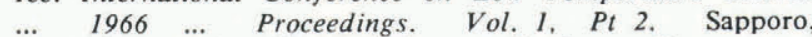
Hokkaido University. Institute of Low Temperature Science, 725-740.

Young, N.W., M. Pourchet, V.M. Kotlyakov, P.A. Korolev, and M.B. Dyugerov. 1982. Accumulation distribution in the IAGP area, Antarctica: $90^{\circ} \mathrm{E}-150^{\circ} \mathrm{E}$. Ann. Glaciol., 3, 333-338. 